\title{
Pathological Internet use and psychiatric disorders: A cross-sectional study on psychiatric phenomenology and clinical relevance of Internet dependency
}

\author{
Bert Theodor te Wildt ${ }^{\star}$ \\ Inken Putzig * \\ Marion Drews* \\ Stefanie Lampen-Imkamp* \\ Markus Zedler* \\ Birgitt Wiese $^{\star}$ \\ Wolfgang Dillo* \\ Martin Detlef OhImeier* \\ * Hannover Medical School, Hannover \\ GERMANY
}

\begin{abstract}
Background and Objectives: With the Cyberspace's exponential growth of influence questions arise about its mental impacts. The presented study examines the question whether the dependent use of the Internet can be understood as an impulse control disorder, an addiction or as a symptom of other psychiatric conditions.

Methods: Internet dependent patients seeking for psychiatric assistance and fulfilling the criteria for pathological Internet use (PIU) were examined with the Structured Clinical Interview according to DSM-IV (SCID), and a variety of questionnaires including the Barratt Impulsiveness Scale (BIS), the Beck Depression Inventory (BDI) and the Dissociative Experience Scale (DES). The patient group was compared to a matched group of healthy controls.

Results: The adult patient-group consisted of 25 subjects, $76 \%$ male, with a mean age of 29.36 years. Average time spent in Cyberspace was $6.47 \mathrm{~h} / \mathrm{d}$, mostly in online-roleplaying games. According to SCID I and BDI, 19 patients (76\%) suffered from a depressive syndrome, with 10 cases of major depressive disorder (40\%) and 8 cases of adjustment disorder with depression (32\%). Six patients (24\%) suffered from a comorbid anxiety disorder. Compared to controls, the patient group presented significantly higher levels of depression (BDI), impulsivity (BIS) and dissociation (DES).

Conclusions: PIU shares common psychopathological features and comorbidities with substance related disorders. Therefore, it might be seen as a diagnostic entity in itself in a spectrum of behavioural and substance dependencies. Especially Internet role play may contain an addictive potential for adolescents and adults with subclinical psychopathology.
\end{abstract}

Received: 23 April 2009

Revised: 30 December 2009

Accepted: 9 February 2010 


\section{Background and objectives}

With the arrival of new media techniques, questions about their addictive potential have always come up with the book having been no exception ${ }^{1}$. However, not even the concept of TV-addiction has stood the test of time, even though some addictive features and a connection with depressive psychopathology may hold valid ${ }^{2}$. With the Internet representing a paradigmatic shift in media technology, merging all media and their analogous contents in one enormous interactive digital media, named Cyberspace, it is questionable, whether the rising excessive Internet use simply represents a novel way of life in a parallel world that competes with human existence in the real world, or if it is also to be viewed as a potentially hazardous way of abuse or addiction comparable to substance abuse disorders ${ }^{3}$.

Within the context of DSM-IV 4 and ICD$10^{5}$ Internet dependency has to be classified as an impulse control disorder (ICD). Accordingly, Kimberly Young, the scientific pioneer in this field ${ }^{6}$, has originally labeled this condition as pathological Internet use (PIU). Yet, as she did herself, other early scientific approaches have already claimed and labeled this phenomenon as an addiction ${ }^{7,8}$, too, even though the term addiction has been eliminated altogether from the psychiatric classification systems a long time ago. The diagnostic entity of ICDs, however, seems to be a rather invalid conceptualization in general $^{9}$, since it combines excessive nonpathological with pathological forms of behaviour such as pyromania and cleptomania, which can be better understood as symptoms of specifically underlying Axis I or II disorders ${ }^{10-12}$. The most convincing diagnostic entity in this context is pathological gambling, to which Internet dependency can be best referred. Conclusively, there is a lack of consent about how Internet dependency -so far the most convincing neutral term to describe the phenomenon- is to be classified diagnostically.

There is a constant rise of publications and studies in this field, revealing striking prevalence rates among other aspects. Two American studies by Greenfield ${ }^{13}$ and Young et al. ${ }^{14}$ showed potentially harmful levels of Internet use in approximately $6 \%$ of users. Lin and Tsai ${ }^{15}$ found a considerably higher rate of people with Internet dependency in a study of Taiwanese students $(11.7 \%)$. In a German study by Hahn and Jerusalem ${ }^{16}$ using the Internet addiction scale (ISS) a lower dependency rate was found in adolescent Internet users $(3.2 \%)$. Especially in the earlier studies, however, the lack of common diagnostic standards may have led to inaccurately high figures. Also, the examined populations were not representative altogether, since they put the focus on specific age and media user groups. However, the data may be taken as a sign, that the existence of Internet dependency as a clinically relevant phenomenon is hardly disputable anymore.

The presented study stems from the hypothesis that the characterization of the psychopathological features and comorbid disorders of Internet dependency may contribute to further determine the phenomenon diagnostically by an in depth examination of a small sample of Internet dependent patients with significant clinical psychopathology.

\section{Methods}

To recruit 25 Internet dependent individuals the study was made public with posters and flyers in the region of Hanover and via Internet, local TV, radio and paper-maga- 
zines, to which 37 individuals responded within 15 months. By the means of a preliminary telephone interview with potential subjects the study's inclusion criteria were tested. Participants had to meet all five of Young's ${ }^{17}$ criteria and at least one of Beard's ${ }^{18}$ additional criteria for Internet Addiction (see table 1).
Moreover, to grant a clinically relevant level of psychopathology, patients had to suffer from a significant level of distress due to their pathological Internet use, measured by the global scales of the Symptom-Checklist (SCL-90R), and recognize the need for psychiatric or psychotherapeutic assistance.

Table 1

Diagnostic criteria for "Internet addiction" according to Beard ${ }^{18}$ as modified from Young's original criteria ${ }^{17}$

\section{Proposed Diagnostic Criteria for Internet Addiction}

\section{All the following criteria (1-5) must be present (Young):}

1. Is preoccupied with the Internet (thinks about previous online activity or anticipates next online session).

2. Needs to use the Internet with increased amounts of time in order to achieve satisfaction.

3. Has made unsuccessful effort to control, cut back, or stop Internet use.

4. Is restless, moody, depressed or irritable when attempting to cut down or stop Internet use.

5. Has stayed online longer than originally intended.

\section{At least one of the following criteria (6-8) must be present (Beard):}

6. Has jeopardized or risked the loss of a significant relationship, job, educational or career opportunity.

7. Has lied to family members, therapist, or others to conceal the extent of involvement with the Internet.

8. Uses the Internet as a way of escaping from problems or of relieving a dysphoric mood (e.g., feelings of helplessness, guilt, anxiety, depression).

The table lists the 8 diagnostic criteria for Internet addiction, which are used world wide most often. They can be of practical use for every reader with a clinical background.

Only physically healthy patients over 18 years of age were accepted for enrollment in the study. Beforehand, informed consent was obtained consistent with the guidelines of the WHO and the declaration of Helsinki. The study's participants did not receive any financial incentive but could expect a thorough diagnostic examination with both a concept and a referral for further psychiatric treatment or counseling.

32 participants fulfilled the study criteria and were invited for an examination in the outpatient department of the Clinic for Psy- chiatry, Social Psychiatry and Psychotherapy at Hanover Medical School. First, a freelance general psychiatric history and examination was conducted by an experienced medical specialist for psychiatry and psychotherapy. Second, the clinical diagnosis was confirmed or adjusted by the Statistical Clinical Interview according to DSM-IV ${ }^{19}$, involving pre- and comorbidity. Third, a test battery of psychometric tests was applied as self reports to further investigate the patients' media use and their psychopathological profile. From the originally 37 patients only 25 $(67.7 \%)$ completed all required examina- 
tions. In addition, 25 healthy control subjects, matched for sex, age and school education, were tested with the same psychometrical paradigm.

The German Internet Addiction Scale (ISS) ${ }^{20}$ was performed to measure the dimensions of pathological Internet use. The validated German version ${ }^{21}$ of the Barratt Impulsiveness Scale (BIS) ${ }^{22}$ served to examine the conceptualization of pathological Internet use as an ICD. Derogatis' Symptom Checklist (SCL-90R) was applied to screen for other psychopathological syndromes and to confirm the patients' clinical level of distress $^{23,24}$. The Beck Depression Inventory (BDI $^{25,26}$ was used to test for depressive symptoms. The Dissociative Experience Scale (DES) ${ }^{27,28}$, the Sense of Coherence Scale (SOC) ${ }^{29,30}$ and the Inventory of Interpersonal Problems (IIP-D) $)^{31,32}$ were meant to detect identity and interpersonal pathology.

The case load estimate of 25 participants per group, calculated with nQuery Advisor 5.0 was based on the BIS as the core psychometric instrument ${ }^{21,22}$. Data was assimi- lated and processed by the means of SPSS 12.1. T-tests for unrelated populations were performed between patient and control group. Correlational calculations were done according to Pearson. A p-value $\leq 0.05$ was considered to be significant.

\section{Results}

Mean age of the patient group was 29.36 years $(S D=10.76)$ with a range from 18 to 55 years and a median of 27 years. Nineteen patients $(76.0 \%)$ were male. Since study and control group were matched for age (Mean = $29.48 ; \mathrm{SD}=9.56)$, sex $(76.0 \%$ males $)$ and school education, which also manifests in a similar level of intelligence (107.4 in patients and 103.3 in controls), there was no significant difference in these aspects. However, eight patients $(34.8 \%)$ were without apprenticeship and occupation, as opposed to the control group, in which everybody was in professional training or a position.

Table 2

Quantitative aspects of media use in comparison between pathological Internet users \& controls

$$
\begin{array}{ccc}
\text { Patient group } & \text { Control group } & \text { Significance } \\
(\mathrm{n}=25) & (\mathrm{n}=25) &
\end{array}
$$

\begin{tabular}{lccccc}
\hline & mean & SD & mean & SD & $\mathrm{p}$ \\
\hline Internet use in years & 7.43 & 3.67 & 5.65 & 2.60 & no significance \\
\hline Internet use in days per week & 6.96 & 0.21 & 3.96 & 2.57 & $\mathrm{p} \leq 0.001$ \\
\hline Internet use in hours per day & 6.47 & 4.07 & 2.20 & 2.52 & $\mathrm{p} \leq 0.001$ \\
\hline Computer game use in years & 13.15 & 6.26 & 12.90 & 6.15 & no significance \\
\hline Computer game play in days per week & 5.90 & 2.02 & 2.06 & 1.33 & no significance \\
\hline Computer game play in hours per day & 6.47 & 5.41 & 1.94 & 0.95 & $\mathrm{p} \leq 0.05$ \\
\hline Number of owned computer games & 38.63 & 60.46 & 17.08 & 34.15 & no significance \\
\hline Number of operating e-Mail-accounts & 4.45 & 2.77 & 2.05 & 2.16 & $\mathrm{p} \leq 0.005$ \\
\hline Number of operating Web-sites & 2.14 & 6.29 & 0.67 & 2.03 & $\mathrm{p} \leq 0.001$ \\
\hline
\end{tabular}

The table is meant to give information on quantitative and qualitative aspects of Internet use. 
As presented in table 2, there was a significant difference $(\mathrm{p} \leq 0.001)$ in average days and hours of private use of the Internet between patients $(6.5 \mathrm{~h} / \mathrm{d}, 6.95 \mathrm{~d} / \mathrm{w})$ and controls $(2.3$ hours, $4.00 \mathrm{~d} / \mathrm{w})$. Patients used computer games also significantly ( $\mathrm{p} \leq 0.05)$ longer $(6.47 \mathrm{~h} / \mathrm{d})$ than controls $(1.94 \mathrm{~h} / \mathrm{d})$. Qualitatively, the patient groups' predominant occupation was playing online games $(60.9 \%)$, while none of the healthy controls were involved in these games. The majority of the patients were playing massively multiplayer online role-playing games $(50.0 \%)$ such as World of Warcraft and, to a lesser degree, multiplayer first person shooters $(35.7 \%)$ such as Counterstrike.

In the Internet Addiction Scale (ISS) the patient group scored significantly higher ( $\mathrm{p} \leq$ 0.01) than the control group (see table 3 ). The BIS also revealed a significant difference $(\mathrm{p} \leq 0.01)$ in the level of impulsivity between patients and controls, however, there was no significant correlation within the patient group between ISS and BIS. In all three psychometric tests measuring variables that are linked to identity (DES, SOC) and interpersonality (IIP) patients scored significantly more pathological $(\mathrm{p} \leq 0.01)$ than controls.

Table 3

Results of psychometric testing in comparison between pathological Internet users and controls

$$
\text { Patient group Control group Significance }
$$

$$
(\mathrm{n}=25) \quad(\mathrm{n}=25)
$$

\begin{tabular}{|c|c|c|c|c|c|}
\hline & mean & $\mathrm{SD}$ & mean & $\mathrm{SD}$ & $\mathrm{p}$ \\
\hline Internet Addiction Scale (ISS) & 53.87 & 13.25 & 24.88 & 6.62 & $\mathrm{p} \leq 0.001$ \\
\hline Barrat Impulsiveness Scale (BIS) & 38.80 & 7.16 & 32.92 & 4.72 & $\mathrm{p} \leq 0.01$ \\
\hline Global Severity Index (GSI) & 0.87 & 0.46 & 0.26 & 0.37 & $\mathrm{p} \leq 0.001$ \\
\hline Positive Symptom Distress Index (PSDI) & 1.80 & 0.43 & 1.26 & 0.32 & $\mathrm{p} \leq 0.001$ \\
\hline Positive Symptom Total (PST) & 42.18 & 18.43 & 15.52 & 17.04 & $\mathrm{p} \leq 0.001$ \\
\hline Somatization (SCL-90R) & 6.67 & 6.01 & 3.20 & 3.95 & $\mathrm{p} \leq 0.05$ \\
\hline Compulsivity (SCL-90R) & 10.54 & 6.25 & 4.04 & 4.94 & $\mathrm{p} \leq 0.001$ \\
\hline Insecurity (SCL-90R) & 10.67 & 6.12 & 2.88 & 4.78 & $\mathrm{p} \leq 0.001$ \\
\hline Depression (SCL-90R) & 15.17 & 6.06 & 3.24 & 6.00 & $\mathrm{p} \leq 0.001$ \\
\hline Anxiety (SCL-90R) & 7.13 & 6.99 & 2.68 & 4.02 & $\mathrm{p} \leq 0.01$ \\
\hline Aggression (SCL-90R) & 4.29 & 3.57 & 1.20 & 1.98 & $\mathrm{p} \leq 0.001$ \\
\hline Phobia (SCL-90R) & 4.45 & 5.56 & 0.65 & 1.19 & $\mathrm{p} \leq 0.01$ \\
\hline Paranoid Ideation (SCL-90R) & 5.50 & 4.60 & 1.68 & 3.05 & $\mathrm{p} \leq 0.001$ \\
\hline Psychoticism (SCL-90R) & 6.63 & 5.05 & 1.40 & 2.80 & $\mathrm{p} \leq 0.001$ \\
\hline Beck Depression Inventory (BDI) & 18.54 & 8.40 & 3.08 & 3.60 & $\mathrm{p} \leq 0.001$ \\
\hline Dissociative Experience Scale (DES) & 13.84 & 13.07 & 5.70 & 7.74 & $\mathrm{p} \leq 0.05$ \\
\hline Sense of Coherence Scale (SOC) & 52.29 & 5.89 & 60.28 & 5.72 & $\mathrm{p} \leq 0.001$ \\
\hline Inventory for Interpersonal Problems (IIP) & 1.46 & 0.58 & 0.63 & 0.48 & $\mathrm{p} \leq 0.001$ \\
\hline
\end{tabular}

In this table the most important psychometric differences between the patients and the control group are listed, which documents both the clinical relevance and the psychopathological complexity of Internet dependency. 
In all global parameters of the SCL-90R indicating a general level of psychopathological burden, patients scored significantly higher ( $\mathrm{p} \leq 0.01$ ) than controls, confirming that the study subjects really suffered from a clinically relevant psychopathology. Patients scored significantly higher $(\mathrm{p} \leq 0.001)$ in 7 of the 9 Subscales of the SCL-90R, i.e. compulsivity, insecurity, depression, aggression, phobia, paranoia and psychosis, with the subscale for depression revealing the highest score in the patient group and the strongest significant difference to the control group. According to the BDI 20 of 25 patients $(80 \%)$ suffered from a depres- sive syndrome. Within the clinical examination and in SCID I those 20 patients revealed a disorder with mainly depressive syptomatology (see figure 1).

Six patients $(24.0 \%)$ suffered from a comorbid anxiety disorder. Two patients $(8.0 \%)$ had a history of substance abuse, but none of the patients were acutely ill in that respect. According to clinical examination and SCID 2 testing, nine patients $(36.0 \%)$ had a comorbid personality disorder, eleven patients $(44.0 \%)$ an accentuated personality structure, with personality types from cluster B (dramaticeccentric) dominant in 14 cases $(56.0 \%)$.

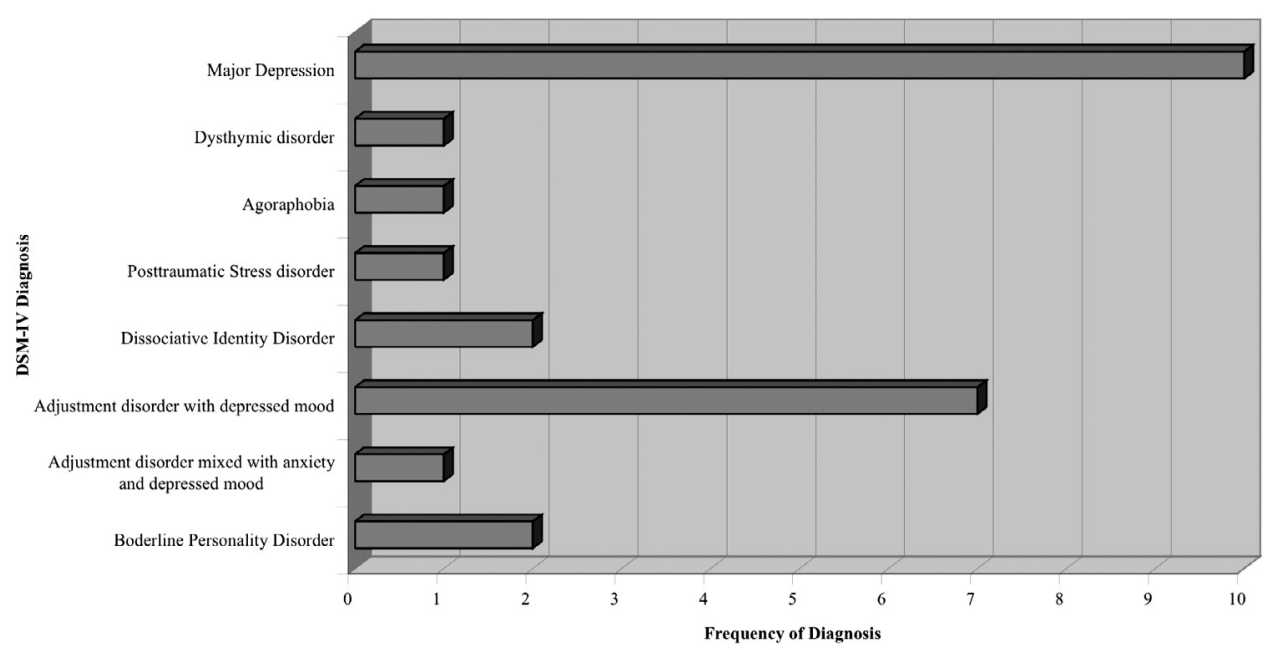

Figure 1. Results of the diagnostic psychiatric assessment and the Structured Clinical Interview (DSM-IV) with the Internet dependent patients: The figure is meant to highlight both the variety of comorbid disorders and the importance of depression in the context of Internet dependency.

\section{Discussion}

The presented study's cross-sectional design prohibits the deduction of causal relations between pathological Internet use
(PIU) and comorbid psychopathology. Its interpretability is also limited by its small sample size. Another small German study by Kratzer and Hegerl ${ }^{33}$ identified relevant comorbid psychiatric pathology in $90 \%$ of 30 PIU-patients, also mostly depressive, anxi- 
ety and personality disorders. However, as opposed to the used computerized Munich Composite International Diagnostic Interview (MCIDI) by Wittchen and Pfister ${ }^{34}$ our study differs with its clinical in depth approach by using psychometric testing, plus a combination of clinical anamnesis and interviewing (SKID), which unfortunately raises the likelihood of an examiner's bias.

According to the vast majority of studies, the average patient presenting with PIU is a young male, failing to grow into a mature adult with complete school education and professional training, financial independency and healthy relationships. Being narcissistically hurt or sociophobically intimidated he has withdrawn himself from real life and escapes into a virtual parallel world, mostly to alleviate his lack of self-esteem and self-confidence by playing the hero he could not be in real life. The presented data however cannot explain, whether a manifest depression or anxiety disorder in this context is to be viewed as cause or effect of PIU, as opposed to personality disorders who are most likely preexisting. As a first conclusion, the high amount of psychiatric comorbidity, which has been confirmed by other studies $^{33-35}$, and the significant level of clinical distress as measured by the global SCL90-R-scales underline the presumption, that the examined individuals with PIU did suffer from a clinically relevant psychopathology.

To conclude that PIU is just a novel symptom of well-known psychiatric diseases is problematic for reasons that rather let it appear as a diagnostic entity of its own comparable with addictions: First, there is a great phenomenal similarity between substance abuse disorders and the so called behavioural addictions, such as PIU ${ }^{36,37}$. Secondly, it is well known, that depression, anxiety and personality disorders are a common comorbidity among substance abusers, especially in alcoholics ${ }^{38,39}$; and in those, according to the diagnostic classification systems, it has become common practice to name comorbid disorders separately, regardless of alleged causal relations ${ }^{40}$. Third, the Internet and especially online-games hold an inherent addictive potential, which is novel for media in general but similar to that of gambling machines ${ }^{41}$. Forth, this addictive potential might push individuals, who may suffer from a subclinical level of depression, anxiety or personality pathology, over the limit to a significant clinical psychopatholo$\mathrm{gy}^{42}$. And lastly, this may be especially relevant for children and adolescents, who ever more often seem to develop a dependency of the Internet, computer games and the combination of the two, also without a distinct comorbid pathology 43,44 .

To extend the chapters for substance abuse to the behavioural addictions has already been proposed for future revisions of the diagnostic classification systems ${ }^{44-46}$. However the syndrome might better be labeled as Internet dependency ${ }^{15,41}$, since the term addiction has been dropped in the favor of dependency in the diagnostic classification systems altogether ${ }^{40}$. Strictly speaking, according to DSM-IV and ICD-10 PIU still would have to be diagnosed as an Impulse control disorder in analogy to Pathological Gambling. Taking into account that the group of the other impulse control disorders seems to be a diagnostic construct rather related with the obsessive-compulsive spectrum of psychopathology ${ }^{26}$, and since in our study PIU did not show a significant correlation with the Barratt Impulsiveness Scale, the hypothesis that its classification as an ICD may be invalid. Yet, despite the questionability of the ICD concept, it might be argued, that the term "Pathological Internet Use" is still of relevance, since it may imply not only quantitatively but also qualitatively excessive use of digital media. 
Yet, against the background of an ever increasing number of young and adult Internet dependent individuals, such as in countries like South Korea and Taiwan ${ }^{35,36}$, it has become undisputable that Internet dependency has to be taken seriously from a medical point of view. To be able to treat the patients adequately and to grant further research, it is necessary to accept it as a diagnostic entity in itself. Therefore, in future revisions of ICD-10 and DSM-IV a group of the so called behavioural addictions should be implemented, containing media dependency. The latter might be more valid in the long run, since not only the Internet but also computer games hold an addictive potential and since we cannot predict, what dangers the ever more quickly changing digital media world may provide in the future.

More research is needed, to exactly understand what makes digital media addictive and what distinguishes a behavioural dependency such as media dependency from substance abuse disorders. Prospective studies are needed to better understand the development of PIU and comorbid psychopathology and that also take into account different media formats and contents.

In the meantime, however, psychiatrists, who have to deal with this novel disease, must not forget to examine the patients for comorbid psychopathology, in order to provide a comprehensive treatment regimen. Yet, to sufficiently understand and treat those patients, psychiatrists also have to be empathically interested in the parallel virtual lifes of their patients. Some patients may need an antidepressant against depression or anxiety, but prospectively, mainly psychotherapeutic approaches, which identify the psychodynamics of the anxious or depressive regression into virtuality and which help to make cognitive and behavioural changes, will help to re-establish patients' real life as an attractive and fulfilling form of existence.

\section{References}

1. te Wildt BT. Psychological impact of the new digital media. Fortschr Neurol Psychiatr 2004; 74: 574-585.

2. Kubey R, Csikszentmihalyi M. Television Addiction is no mere metaphor. Sci Am 2002; 286: 62-68.

3. Mitchell P. Internet addiction: Genuine diagnosis or not? Lancet 2000; 355: 632.

4. American Psychiatric Association. Diagnostic statistical manual of mental disorders: DSM-IV.TR: Diagnostic and Statistical Manual of Mental Disorders. Arlington: American Psychiatric Publishing; 1994.

5. WHO. ICD-10 Classification of Mental and Behavioural Disorders: Clinical Despriptions and Diagnostic Guidelines. Genf: WHO; 1992.

6. Young KS. What makes the Internet Addictive: Potential Explanations for Pathological Internet Use. Paper presented at the $105^{\text {th }}$ annual conference of the American Psychological Association, August 15, 1997, Chicago, IL.

7. Greenfield DN. Virtual Addiction. Oakland: New Harbinger; 1999.

8. Bai YM, Lin CC, Chen JY. Internet addiction disorder among clients of a virtual clinic. Psychiatr Serv 2001; 52: 1397.

9. Herpertz S, Sass H. Impulsiveness and impulse control. On the psychological and psychopathological conceptualization. Nervenarzt 1997; 68: 171-183.

10. Grant JE, Levine L, Kim D, Potenza MN. Impulse Control Disorders in Adult Psychiatric Inpatients. Am J Psychiatry 2005; 162: 2184-2188.

11. Grant JE. Understanding and Treating Kleptomania: New Models and New Treatments. Isr J Psychiatry Relat Sci 2006; 43: 81-87.

12. Grant JE, Kim SU. Clinical Characteristics and Psychiatric Comorbidity of Pyromania. J Clin Psychiatry 2007; 68: 1717-1722.

13. Aboujaoude E, Koran LM, Gamel N, Large MD, Serpe RT. Potential Markers for Problematic Internet Use: A Telephone Survey of 2,513 Adults. CNS Spectr 2006; 11 : 750-755.

14. Young KS. Internet addiction: The emergence of a new clinical disorder. Cyberpsychol Behav 1996; 1: 237-244.

15. Lin SS, Tsai CC. Sensation seeking and Internet dependence of Taiwanese high school adolescents. Computers in human behavior 2002; 18: 411-426.

16. Hahn A, Jerusalem M. Internetsucht: Jugendliche gefangen im Netz. In: Raithel J (Ed.). Risikoverhalten Jugendlicher. Opladen: Leske \& Budrich; 2001. 
17. Young KS, Pistner M, O'Mara, Buchanan J. Cyber Disorders: The Mental Health Concern for the New Millenium. CyberPsychology \& Behavior 2000; 3: 475-479.

18. Beard KW, Wolf EM. Modification in the Proposed Diagnostic Criteria for Internet Addiction. Cyberpsychol Behav 2001; 4: 377-383.

19. First MB, Spitzer R, Gibbon M. Structured Clinial Interview for DSM-IV-R Axis I Disorders (SCID-I), Clinican Version, User's Guide. Arlington: Amer Psychiatric Pub Inc; 1996.

20. Hahn A, Jerusalem M. Internetsucht: Reliabilität und Validität in der Online-Forschung. In: Theobald A, Dreyer M, Starsetzki T (Eds.). Online-Marktforschung. Beiträge aus Wissenschaft und Praxis. Wiesbaden: Gabler; 2001.

21. Preuss U, Rujescu D, Giegling I, Koller G, Bottlender M, Engel R, et al. Evaluation der deutschen Version der Barratt Impulsiveness Scale (BIS 5). Fortschr Neurol Psychiatr 2003; 71: 527-534.

22. Patton JM, Stanford MS, Barrattt ES. Factor Structure of the Barrattt Impulsiveness Scale. J Clin Psychol 1995; 51: 768-774.

23. Hessel A, Schumacher J, Greyer M, Brähler E. Symptom-Checkliste SCL-90R: Testtheoretische Überprüfung und Normierung an einer bevölkerungsrepräsentativen Stichprobe. Diagnostica 2001; 47: 27-39.

24. Derogatis LR, Cleary PA. Confirmation of the dimensional structure of the SCL-90: A study in construct validation. J Clin Psychol 1977; 33: 981-989.

25. Beck AT, Ward CH, Mendelson M, Mock J, Erbaugh J. Arch Gen Psychiatry 1961; 4: 561-571.

26. Hautzinger M, Bailer M, Worall H, Keller F. Becks Depressionsinventar. Testhandbuch. Bern: Gruber; 1995.

27. Bernstein EM, Putnam FW. Development, reliability, and validity of a dissociation scale. J Nerv Ment Dis 1986; 174: 727-735.

28. Freyberger HJ, Spitzer C, Stieglitz RD, Kuhn G, Magdeburg N, Bernstein-Carlson E. Fragebogen zu dissoziativen Symptomen (FDS). Deutsche Adaptotion. Reliabilität und Validität der amerikanischen Dissociative Experience Scale (DES). Psychother Psychosom Med Psychol 1998; 48: 223-229.

29. Eriksson M, Lindstöm B. Validity of Antonovsky's sense of coherence scale: a systematic review. J Epidemiol Community Health 2005; 59: 460-466.

30. Schumacher J, Gunzelmann T, Brähler E. Deutsche Normierung der Sense of Coherence Scale von Antonovsky. Diagnostica 2000; 46: 208-213.
31. Gude T, Moum T, Kaldestad E, Friis S. Inventory of interpersonal problems: a three dimensional balanced and scalable 48-item version. J Pers Assess 2000; 74: 296-310.

32. Brähler E, Horowitz LM, Kordy H, Schumacher J, Strauß B. Zur Validierung des Inventars zur Erfassung Interpersonaler Probleme (IIP), Ergebnisse einer Repräsentativbefragung in Ost- und Westdeutschland. Psychother Psychosom Med Psychol 1999; 49: 422-431.

33. Kratzer S, Hegerl U. Is, "Internet Addiction" a disorder of ist own? A Study on subjects with excessive Internet use. Psychiatr Prax 2008; 35: 80-83.

34. Wittchen HU. Reliability and validity studies of the WHO-Composite International Diagnostic Interview (CIDI): A critical review. J Psychiatr Res 1994; 28: 57-84.

35. Ha JH, Yoo HJ, Cho IH, Chin B, Shin D, Kim JH. Psychiatric comorbidty assessed in Korean children and adolescents who screen posititve for Internet addiction. J Clin Psychiatry 2006; 67: 821-826.

36. Yen JY, Ko CH, Yen CF, Chen SH, Chung WL, Chen CC. Psychiatric Symptoms in adolescents with Internet addiction: Comparison with substance use. Psychiatry Clin Neurosci 2008; 62: 9-16.

37. Wesphal J. Emerging Conceptual Models of Excessive Behaviors. Int J Ment Health Addiction 2007; 5: 107-116.

38. Arolt V, Driessen M. Alcoholism and Psychiatric Comorbidity in General Hospital Inpatients. Gen Hosp Psychiatry 1996; 18: 271-277.

39. Zilberman ML, Tavares H, Blume SB, el-Guebaly N. Substance use disorders: Sex differences and psychiatric comorbidities. Can J Psychiatry 2003; 48: 5-13.

40. Hasin D, Hatzenbuehler ML, Keyes K, Ogburn E. Substance use disorders: Diagnostic and Statistical Manual of Mental Disorders, fourth edition (DSM-IV) and International Classification of Diseases, tenth edition (ICD-10). Addiction 2006; 101 (S1): 59-75.

41. Griffiths MD, Hunt N. Dependence on Computer Games by Adolescents. Psychological Reports 1999; 82: 475-480.

42. Ratey JJ, Johnson C. Shadow Syndromes. The Mild Forms of Major Mental Disorders That Sabotage Us. New York: Bantam Doubleday Dell; 1998.

43. Rehbein F, Kleimann M, Mössle T. Computerspielabhängigkeit im Kindes- und Jugendalter. Hannover: Kriminologisches Forschungsinstitut; Forschungsbericht Nr. 108; 2009.

44. Hur MH. Demographic, habitual, and socioeconomic determinants of Internet addiction disorder: an empirical study of Korean teengagers. Cyberpsychol Behav 2006; 9: 514-525. 
45. Wesphal J. Emerging Conceptual Models of Excessive Behaviors. Int J Ment Health Addiction 2007; 5: 107-116.

46. Dell'Osso B, Altamura C, Allen A, Marazziti D, Hollander E. Epidemiologic and clinical updates on impulse control disorders. A critical review. Eur Arch Psychiatry Clin Neurosci 2006; 256: 464-475.

\author{
Address for correspondence: \\ PD Dr. med. Bert Theodor te Wildt \\ Department of Psychiatry, Social Psychiatry and \\ Psychotherapy \\ Hanover Medical School \\ 30625 Hannover (Germany) \\ Tel.: 0049- 511-532-3167 \\ Fax: 0049-511-532-2415 \\ E-mail: tewildt.bert@mh-hannover.de
}

None of the contributing authors have been in any conflict of interest since the study has been financed fully by the Medical Scholl Hannover's independent research fund and since there have been no commercially used products involved. All named authors have provided a significant contribution to the presented study. The study has been approved by Hannover Medical Schol's own ethics committee. 